\title{
COVID and Cardiovascular Disease: What We Know in 2021
}

\author{
Michael Chilazi $^{1} \cdot$ Eamon Y. Duffy $^{1} \cdot$ Aarti Thakkar $^{1} \cdot$ Erin D. Michos $^{1,2,3,4}$ (D \\ Accepted: 29 April 2021 / Published online: 13 May 2021 \\ (C) The Author(s), under exclusive licence to Springer Science+Business Media, LLC, part of Springer Nature 2021
}

\begin{abstract}
Purpose of Review Coronavirus disease 2019 (COVID-19) has been the cause of significant global morbidity and mortality. Here, we review the literature to date of the short-term and long-term consequences of Severe Acute Respiratory Syndrome Coronavirus-2 (SARS-CoV-2) infection on the heart.

Recent Findings Early case reports described a spectrum of cardiovascular manifestations of COVID-19, including myocarditis, stress cardiomyopathy, myocardial infarction, and arrhythmia. However, in most cases, myocardial injury in COVID-19 appears to be predominantly mediated by the severity of critical illness rather than direct injury to myocardium from viral particles. While cardiac magnetic resonance imaging remains a powerful tool for diagnosing acute myocarditis, it should be used judiciously in light of low baseline prevalence of myocarditis. Guiding an athletic patient through return to play (RTP) after COVID-19 infection is a challenging process. More recent data show RTP has been a safe endeavor using a screening protocol. "Long COVID" or post-acute sequelae of SARS-CoV-2 infection has also been described. The reported symptoms span a large breadth of cardiopulmonary and neurologic complaints including fatigue, palpitations, chest pain, breathlessness, brain fog, and dysautonomia including postural tachycardia syndrome (POTS). Management of POTS/dysautonomia primarily centers on education, exercise, and salt and fluid repletion.

Summary Our understanding of the impact of COVID-19 on the cardiovascular system is constantly evolving. As we enter a new age of survivorship, additional research is needed to catalogue the burden of persistent cardiopulmonary symptoms. Research is also needed to learn how acute management may alter the likelihood and prevalence of this chronic syndrome.
\end{abstract}

Keywords COVID-19 - Cardiovascular disease $\cdot$ SARS-CoV2 $\cdot$ Return to play $\cdot$ Long COVID

This article is part of the Topical Collection on Coronary Heart Disease

Erin D. Michos

edonnell@jhmi.edu

Michael Chilazi

mchilazi@jhmi.edu

Eamon Y. Duffy

eduffy4@jhmi.edu

Aarti Thakkar

athakka2@jhmi.edu

1 Department of Medicine, Johns Hopkins University School of Medicine, Baltimore, MD, USA

2 Johns Hopkins Ciccarone Center for the Prevention of Cardiovascular Disease, Johns Hopkins University School of Medicine, Baltimore, MD, USA

3 Welch Center for Prevention, Epidemiology and Clinical Research, Johns Hopkins University, Baltimore, MD, USA

4 Division of Cardiology, Johns Hopkins Hospital, 600 N. Wolfe Street, Blalock 524-B, Baltimore, MD 21287, USA

\section{Introduction}

In the year 2020, the Coronavirus disease 2019 (COVID-19) was the third leading cause of death with an estimated 345,323 deaths in the USA [1]. Perhaps more than any other communicable disease, COVID-19 has captivated the cardiology community due to its apparent links with cardiovascular disease (CVD) [2•, 3-5]. The novelty of the virus led to early reliance on small case reports and theoretical explanations to explain and predict the impact on CVD. Now, more than a year since the pandemic's onset, more mature studies have emerged that refine our understanding of the interplay between COVID-19 and the heart.

Early in the pandemic, patients with cardiovascular comorbidities proved most vulnerable to severe infection $[3,6]$. The specificity of Severe Acute Respiratory Syndrome Coronavirus 2 (SARS-CoV-2) for the angiotensinconverting enzyme-2 (ACE-2) protein fueled further concerns about injury to the cardiovascular system $[3,7]$ and triggered fears about concurrent use of drugs including angiotensin- 
converting enzyme inhibitors and angiotensin receptor blockers [8•]. Early case reports described a spectrum of cardiovascular manifestations of COVID-19 infection, including myocarditis, stress cardiomyopathy, myocardial infarction (MI), and arrhythmia [9-12]. In combating a novel disease, the cardiology community deployed its most advanced technology including cardiac magnetic resonance imaging (CMR) which has characterized acute and chronic consequences of SARS-CoV-2 infection [13, 14], but often the findings have left clinicians with more questions than answers.

Now more than a year since the first reported cases in 2020, the global community finds itself at a critical point in the timeline of the pandemic. With survivors outnumbering those infected and with vaccines in distribution, further attention can be paid to the long-term cardiovascular effects of COVID-19. Nonetheless, as surges continue across the world owing to new variants and a lag in vaccine distribution, the medical community must remain apprised of the latest evidencebased management of acute COVID-19 infection.

Our understanding of the impact of COVID-19 on the cardiovascular system is constantly evolving. The rapid pace of the pandemic and the body of research it has spawned requires clinicians to adapt management in real time. Herein, we review the latest literature through April 1, 2021 to refine our current understanding of the acute and long-term consequences of COVID-19 infection on the cardiovascular system. In acute infection, we revisit our current understanding of mechanisms of myocardial injury in COVID-19 infection, the prognostic implications of troponin elevation, and indications for CMR in diagnosis and management. In resolved infection, we review considerations for special populations such as athletes regarding safe return to play, as well as those with lingering cardiopulmonary symptoms colloquially known as "long COVID." We conclude by proposing future areas of investigation for the interaction between COVID-19 and CVD.

\section{Part I: Acute Infection}

\section{Mechanisms of Cardiac Injury in COVID-19}

Cardiac troponin is a highly specific test for myocardial injury, which can be measured by conventional or high-sensitivity assays. Notably, an elevated troponin (defined as being above the 99th percentile of upper reference limit) does not necessarily equate to an MI. According to the 4th universal definition, the criteria for an MI requires a rise/fall pattern of troponin with at least one value above the 99th percentile along with other symptoms or signs of ischemia [15]. A type $1 \mathrm{MI}$ occurs from an acute plaque rupture/erosion event, which has also been seen in the setting of other viral infections $[4,16]$, whereas a type $2 \mathrm{MI}$ is from "demand ischemia" in the context of an oxygen demand/supply mismatch stemming from stressors such as hypoxia, hypoperfusion, and tachycardia, which can occur in COVID-19, as well as other critical illnesses. Both types of MIs have been reported in COVID-19 [2•]. However, paradoxically, there was an approximate $20 \%$ reduction in ST-elevation myocardial infarction (STEMI) rates during the COVID-19 pandemic. Alternate mechanisms behind this STEMI reduction have been postulated, but the leading concern was that patients were avoiding hospital care for fear of contracting the virus. Beyond acute MI, troponin elevation can accompany a number of other COVID-19 cardiovascular presentations including viral myocarditis, indirect cardiac injury from cytokine storm, stress cardiomyopathy, heart failure (HF), pulmonary embolism, and arrhythmias, or reflect pre-existing CVD or cardiac structural abnormalities $[17 \bullet, 18]$.

The prevalence of cardiac injury, as measured by an elevated cardiac troponin, on the order of $20-40 \%$ among the first reported patients with severe (hospitalized) COVID-19 attracted the attention of the cardiology and medical community at large $[6,17 \bullet, 18-23,24 \bullet, 25]$. As the virology of SARS-CoV-2 was further elucidated, its interaction with the ACE2 protein found on cardiomyocytes supported the physiologic plausibility of direct cardiac viral injury [7]. A precedent had been established by a related coronavirus, SARSCoV-1, causing the first SARS outbreak in Asia, whereby viral RNA in cardiac tissue had been isolated [26]. Furthermore, individuals with CVD, such coronary artery disease (CAD) and HF [27, 28], and those with CVD risk factors including hypertension, diabetes, and obesity [27, 29-31] proved more susceptible to severe infection, heightening concerns that the heart may be a direct viral target and rendered more vulnerable if compromised.

With respect to the etiology of myocardial injury in COVID-19, our understanding has evolved since the onset of the outbreak. Larger histopathologic studies have challenged early frameworks of cardiac injury, demonstrating the prevalence of myocarditis and direct viral toxicity to myocytes to be exceedingly rare $[32 \bullet \bullet, 33]$. In one of the largest cardiac autopsy series to date, Lindner and colleagues demonstrated that while viral RNA was isolated in cardiac tissue, in situ hybridization localized the site of infection not to cardiomyocytes, but rather the interstitium and infiltrating macrophages [32••]. Additionally, there were zero confirmed cases of myocarditis by the Dallas criteria. Other pathologic studies have also failed to document direct cardiomyocyte infection [33, 34].

Notably, as features of the novel coronavirus were rapidly catalogued early in the pandemic, little was done to compare against appropriate control groups. Recent research has situated COVID-19 in the context of the broader critical care landscape. Metkus and colleagues compared troponin elevation in COVID-19 acute respiratory distress syndrome (ARDS) versus non-COVID-19 ARDS among nearly 250 
intubated patients across a large hospital system and demonstrated that myocardial injury was actually less common in COVID-19 than non-COVID-19 ARDS, after accounting for the degree of critical illness and organ dysfunction [35••]. Patients with COVID-19 had worse oxygenation and hemodynamics, reinforcing indirect cardiac injury secondary to critical illness as the more likely mechanism at play [36]. These findings are further reinforced by high rates of myocardial injury seen in other systemic infections beyond COVID-19, including sepsis, documented in the critical care literature [37-39].

While other cardiac manifestations including myocarditis, stress cardiomyopathy, and MI have been described in COVID-19 and should not be discounted [2, 9-12], situating COVID-19 in the context of other critical illness has recalibrated our understanding of myocardial injury to recognize more prevalent mechanisms such as hypoxemia and hemodynamic compromise (Fig. 1).

Although myocardial injury in COVID-19 may not be unique to the virus, the degree of critical illness that it can cause speaks to unique pathogenic attributes. The responsible mechanism is likely related to its ability to stimulate a robust inflammatory response. In studies of myocardial injury in COVID-19, predictors of troponin elevation consistently demonstrated associations with inflammatory markers, including C-reactive protein (CRP), D-dimer, ferritin, and fibrinogen $[19,35 \cdot \bullet, 40]$. Pathology studies have supported this relationship by demonstrating greater expression of cytokines with higher viral loads [32•*]. While the hyper-inflammatory phase inflicts much of the respiratory and circulatory compromise mediating indirect myocardial injury in severe infection, inflammation is previously known to directly mediate CVD, as seen in atherosclerosis and other hyper-inflammatory states including sepsis and hemophagocytic lymphohistiocytosis (HLH) [41]. Cardiomyocytes express receptors to cytokines including tumor necrosis factor and interleukin-6, the effects of which can reduce inotropy secondary to alterations in catecholamine signaling and cause cytotoxic injury [42]. Moreover, cytokines alter the vascular endothelium to promote inflammatory migration and can cause endothelitis, microthrombi, and microvascular injury which have been described in COVID-19 [34].

Echocardiography has further refined our understanding of myocardial damage in COVID-19, detailing certain functional patterns of injury [14]. Szekely and colleagues found right ventricular (RV) dysfunction to be the most common echocardiographic abnormality in a series of 100 hospitalized COVID-19 patients, among nearly 40\%, with RV deterioration most associated with clinical decompensations [43]. RV dysfunction was also the most common abnormality seen in a multi-center international cohort of over 300 hospitalized patients with COVID-19, around 26\% [44]. A full spectrum of dysfunction was seen in both studies, however, including global and regional left ventricular (LV) systolic dysfunction,
Fig. 1 Symbolic pie chart illustrating common causes of indirect myocardial injury and more rare causes of direct myocardial injury in COVID-19 infection

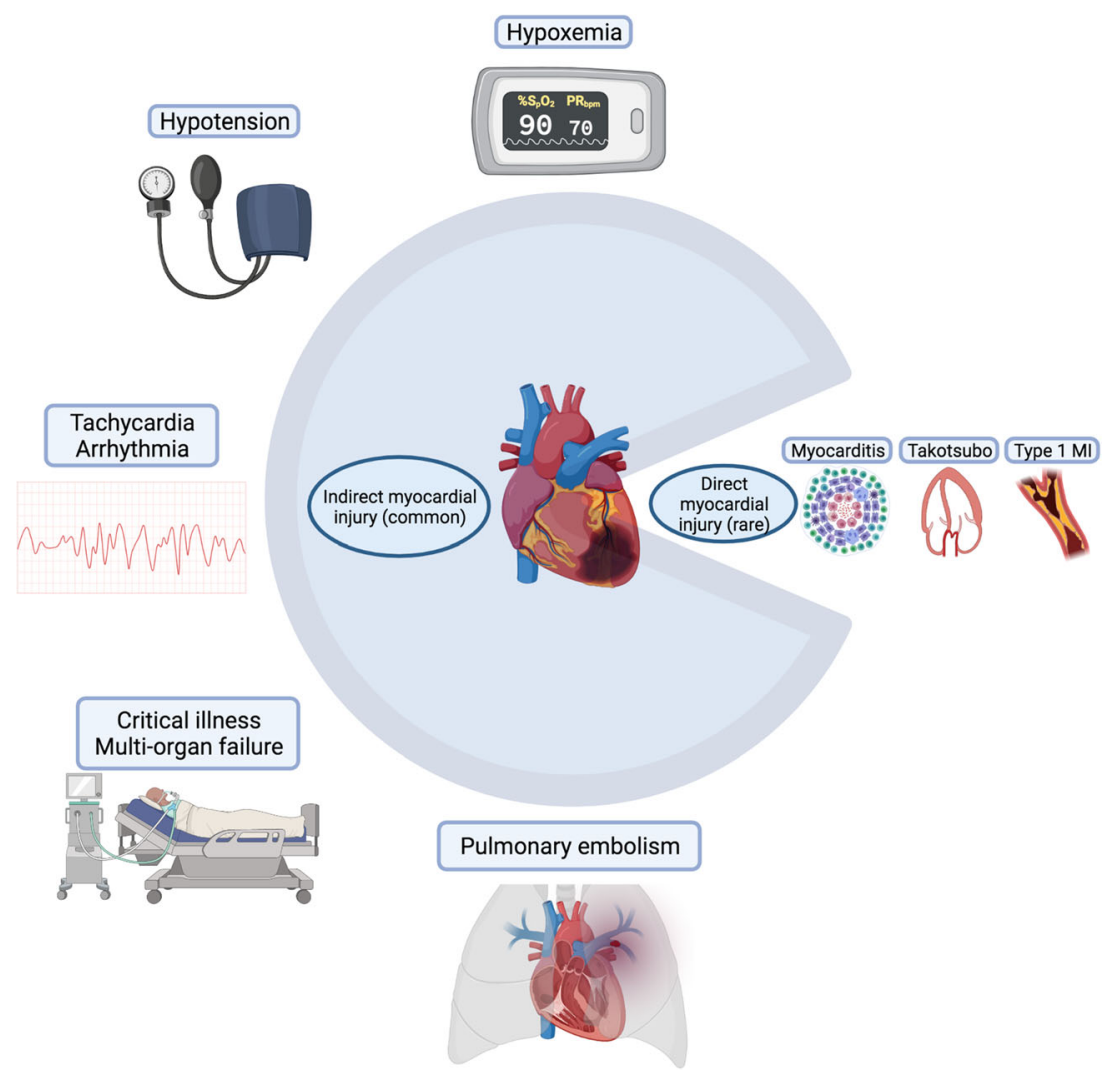


diastolic dysfunction, and pericardial effusions. The prevalence of RV dysfunction speaks to COVID-19 being a predominantly respiratory pathogen with a tendency for deep venous thrombosis and pulmonary embolism, all of which can compromise pulmonary vascular resistance and increase RV loading conditions. Use of speckle-tracking echocardiography found reduced basal longitudinal strain to be present in $52 \%$ of patients in one single-center study; patients who were obese, Black patients, or patients with hypertension and diabetes were more likely to present with this functional pattern [45]. Future studies are needed to determine whether these functional changes are unique to COVID-19 or also seen in other forms of ARDS and critical illness.

\section{Troponin Elevation: Prognostic Implications}

Mechanism of injury aside, detectable troponin elevation carries prognostic value in acute COVID-19 infection. Shi and colleagues were among the first to report higher mortality in those with troponin elevation from a single-center cohort in Wuhan, finding a threefold to fourfold risk of death [19]. Later, Lombardi and colleagues validated these findings in a multi-center cohort in Italy with over 600 patients, albeit with a more attenuated hazard ratio of 1.7 [25]. In one of the most diverse cohorts studied with over 2000 patients admitted to a New York City hospital system, Smilowitz and colleagues illustrated that the risk of death was twofold higher among patients with troponin elevation [46]. Importantly, the degree of troponin elevation was associated with more severe critical illness (defined as ICU admission, need for mechanical ventilation, discharge to hospice, or death). While these seminal studies defined troponin elevation as greater than the 99th percentile of the upper limit of normal, Qin and colleagues illustrated that troponin elevation in COVID-19 infection was associated with mortality even at thresholds $19-50 \%$ lower than those traditionally used in clinical settings [47].

Moreover, risk for mortality and adverse outcomes appears continuous with the degree of troponin elevation; higher troponin continues to amplify risk, providing clinicians with a quantitative not just qualitative risk assessment for patients [24•]. As such, measuring troponin for hospitalized COVID19 patients has been integrated into routine clinical practice and management algorithms. For hospitals, it serves to forecast trajectory and identify patients that may require more intensive resources particularly in times of scarcity [48]. Several society guidelines including the World Health Organization and the Chinese Clinical Guidance for COVID-19 recommend measuring troponin for all admitted patients, while others including the American College of Cardiology (ACC) recommend testing when clinically indicated [22].

The association between troponin elevation and mortality spurred debate whether myocardial injury is a mediator or a marker of adverse outcomes. In their comparison between COVID and non-COVID ARDS, Metkus and colleagues demonstrated that troponin elevation was no longer associated with mortality after controlling for age, sex, and, importantly, multiorgan system dysfunction [35••]. Moreover, Giustino and colleagues have suggested that the presence of troponin elevation alone may not be sensitive enough to detect clinically meaningful myocardial injury [44]. In a retrospective, multi-center international study of echocardiographic findings in over 300 hospitalized patients with COVID-19, only those with troponin elevation and echocardiographic abnormalities, not troponin elevation alone, had significantly higher risk of in-hospital mortality [44]. These findings suggest that myocardial injury evidenced by detectable troponin, akin to other markers including lactate, creatinine, and bilirubin, is often the consequence, rather than the cause of, critical illness and reflects the frailty of the underlying substrate.

\section{Role of Cardiac Magnetic Resonance Imaging}

The pathophysiologic plausibility of COVID-19 causing direct myocardial infection and early case reports invoking myocarditis led to increased interest in use of CMR, now the preferred non-invasive diagnostic modality for acute myocarditis [49]. The first case reports of myocarditis in acute COVID-19 infection reported prevalence of about 7\% [50, 51]; however, these studies were flawed by inconsistent diagnostic criteria and limited sample sizes. As discussed previously in the context of histopathologic studies, the prevalence of myocarditis in COVID-19 is now appreciated to be extremely rare, and larger retrospective multi-center cohort studies have found it to be $1 \%$ or less [52]. Recognizing the low pre-test probability of COVID-19 myocarditis and considering more likely causes of myocardial injury inform the appropriate use of CMR. In particular with CMR, the lengthier examination time and logistics required to accommodate exams in intubated patients (including transitioning patients to and from scanner-safe ventilators) increase exposure risk for healthcare workers [53].

Subsequently, society guidelines for appropriate use of CMR during COVID-19 infection have emphasized the consideration of alternative diagnoses and recommended use only when findings will alter management. The Society of Cardiovascular Magnetic Resonance (SCMR) endorses the use of CMR in COVID-19 infection when results have immediate procedural implications, including but not limited to revascularization, valvular interventions, necessary ablations, immunosuppression, or concern for malignancy requiring cardiothoracic surgery [54]. When new LV dysfunction or clinical symptoms (e.g., chest pain, arrhythmia) raise concern for myocarditis, an expert panel from the ACC recommends CMR only after CAD has been ruled out by angiography or less invasive modalities such as coronary computed 
tomography angiography (CCTA), because the pre-test probability of ischemia is much more likely than acute myocarditis $\left[55^{\bullet}\right]$

There may be even greater interest in CMR for the surveillance of survivors following acute infection. Huang and colleagues were the first to demonstrate myocardial edema and fibrosis, evidenced by abnormal T1/T2 signaling and late gadolinium enhancement (LGE), respectively, in a small sample of 26 patients who continued to report cardiac symptoms 50 days from symptom onset [56]. Later, in a prospective cohort study of 100 unselected patients (i.e., did not necessarily present with cardiac symptoms), Puntmann and colleagues demonstrated ongoing myocardial inflammation in $60 \%$ of patients at a median follow-up of 71 days [13]. These findings raised alarm for long-term consequences for the general population (of note, two-thirds of the participants were not hospitalized) as well as select individuals, namely athletes, to be explored in the subsequent section. Importantly, these studies did not examine clinical outcomes related to these findings which remains an important area of investigation. Moreover, additional work is needed to compare myocardial injury following COVID-19 infection with controls beyond healthy individuals, because similar CMR findings have been described following other infectious syndromes such as sepsis [57]. Recommendations for CMR in COVID-19 infection are summarized in Fig. 2.

\section{Part II: Resolved Infection}

\section{COVID-19 and Return to Play for Athletes}

The question of when a competitive athlete can return to play (RTP) after COVID-19 infection poses an urgent and important challenge to the field of cardiology. The urgency is driven by the fact that athletic organizations, from the professional to the recreational, were some of the first to return to full speed during the pandemic. This collective rush to return began with little data on how to do so safely after an infection. The importance was clear, as myocarditis is a potential sequela of COVID-19 infection and a cause of death in young athletes [58]. Exercising with an active myocarditis can lead to increased inflammation and a proarrhythmogenic milieu. Furthermore, the athletic heart can have abnormalities in size, function, and response to exercise that make it challenging to distinguish from the inflamed or injured heart [59]. Intense exercise can lead to transient elevations in troponins and imaging findings suggestive of cardiac fatigue and myocardial inflammation [60]. With thousands of athletes eager to return to action, how to do so safely became a central issue in the field of cardiology throughout the pandemic.

In May of 2020, the ACC's Sports and Exercise Cardiology Section issued its first set of RTP recommendations [61]. For those athletes that experienced a symptomatic infection, they recommended a 2 -week rest period after symptom resolution, a cardiac evaluation (electrocardiogram, echocardiogram, or high-sensitivity troponin), and additional cardiac imaging with any abnormalities. If myocarditis was detected, clinicians were referred to existing American Heart Association (AHA)/ACC myocarditis guidelines which recommend abstaining from athletics for 3-6 months [62]. Six months later, the Section updated and expanded these guidelines to include specific recommendations based on age and detailed troponin and CMR screening recommendations [63]. An Expert Consensus Statement followed, both of which recommended against the use of CMRbased screening of all athletes with prior COVID-19 infection [64].

The use of CMR in the RTP setting received much attention. Published in September of 2020, Rajpal and colleagues performed CMR in 26 competitive athletes and found that 4 (15\%) had CMR findings suggestive of myocarditis and 8 additional athletes (30.8\%) exhibited LGE without T2 elevation suggestive of prior myocardial injury [65]. Brito and colleagues then published a study of imaging findings (echocardiography and CMR) of 54 student athletes who were recovering from COVID-19 infection [66]. They concluded that more than 1 in 3 previously healthy college athletes recovering from COVID-19 infection showed imaging features of resolving pericardial inflammation. These studies are limited in their size and lack of a control group or clinical endpoints, but they raised the alarm further for RTP safety, particularly at the collegiate level.

Fortunately, more recent registry data shows the national RTP has been a safe endeavor. A study of 789 professional athletes that underwent a RTP cardiac testing protocol after COVID-19 infection found imaging evidence of inflammatory heart disease in 5 athletes $(0.6 \%)[67 \bullet \bullet]$. The cardiac screening protocol included troponin, ECG, and transthoracic echocardiogram; CMR or stress echocardiography was pursued only in athletes with abnormal initial cardiac screening. No adverse cardiac events occurred in athletes who underwent cardiac screening and returned to play.

Guiding a patient through the return to athletics after COVID-19 infection is a challenging process. COVID-19 data evolves rapidly, sports cardiology is a relatively nascent field, and the athletic heart is a unique substrate. This combines to produce more uncertainty than clear answers when approaching the return to play. However, as time has passed and more data emerged, that return, when guided by the current screening recommendations, can be done safely.

\section{Long COVID}

As healthcare workers and researchers are continuing to learn, triage, and treat the acute cardiovascular risks of COVID-19, 
Fig. 2 Review of the role and indications for cardiac magnetic resonance (CMR) imaging in acute and resolved infection, both in the general population and more specifically in athletes. Abbreviations: LV left ventricular, ACS acute coronary syndrome, CCTA coronary computed tomography angiography, TTE transthoracic echocardiography, EKG electrocardiogram

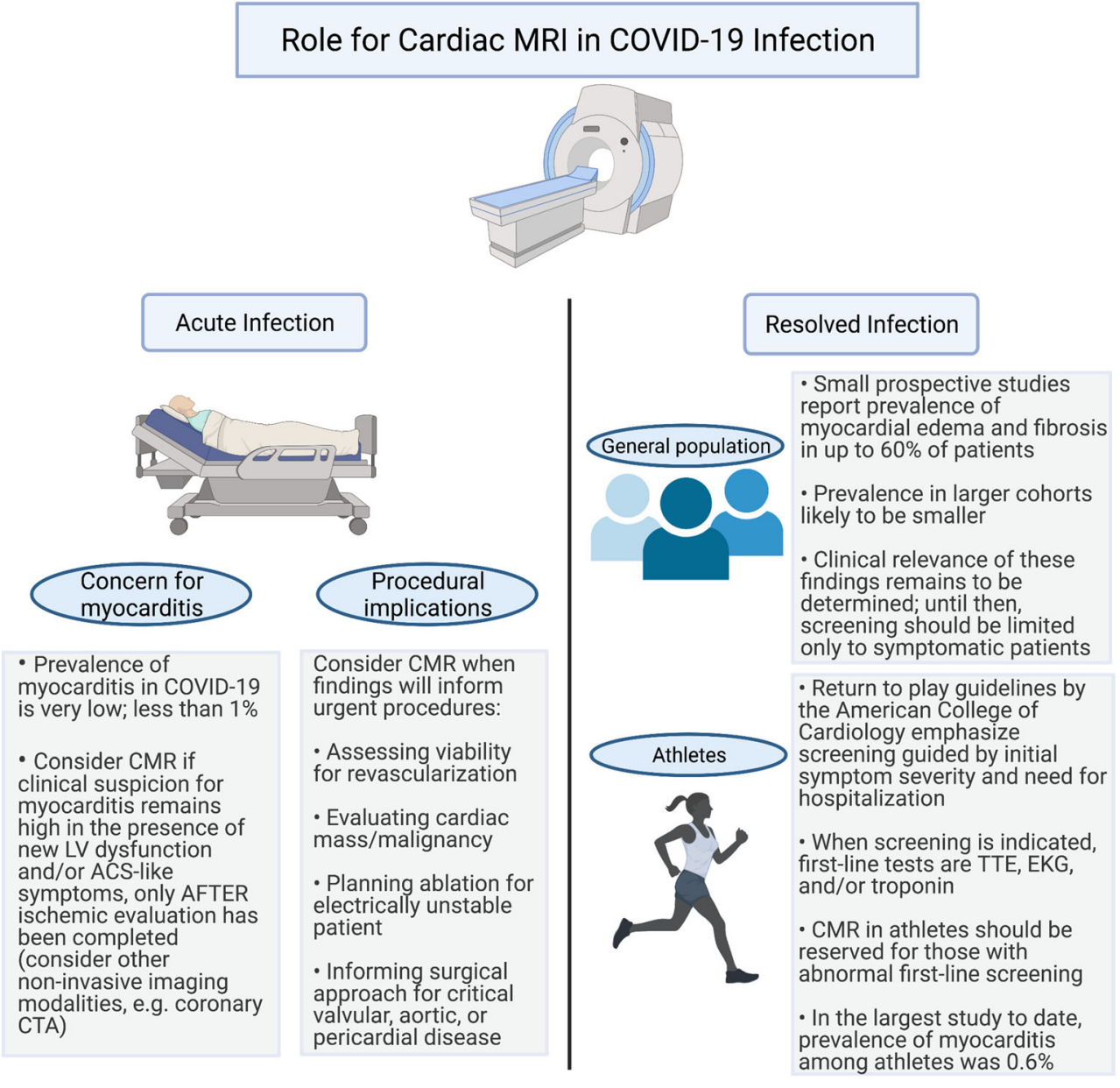

many outpatient providers are being inundated by patients with persistent symptoms after acute infection, known in popular media as "long COVID" [68]. With greater recognition of this ongoing syndrome, researchers have established the following definitions: post-acute COVID syndrome (PACS) for persistent symptoms after 3 weeks and chronic COVID after 12 weeks $[69,70]$. The National Institutes of Health has also referred to "long COVID" as post-acute sequelae of SARSCoV-2 infection (PASC) [71]. The reported symptoms span a large breadth of cardiopulmonary and neurologic complaints including fatigue, palpitations, chest pain, breathlessness, brain fog, and dysautonomia [69, 70, 72-75].

Researchers have been studying the persistent effects of COVID-19 since the early days of the pandemic. Of a cohort of 143 discharged patients in Italy from April 2020, 87\% reported ongoing fatigue and dyspnea at 60 days [76]. Halpin and colleagues in the United Kingdom (UK) demonstrated that patients requiring intensive care unit-level care were more likely than general ward patients to report persistent symptoms of fatigue ( $72 \%$ verses $60.3 \%$ ) and breathlessness $(65.6 \%$ vs $42.6 \%)$ after discharge [72]. Another larger cohort in Michigan found that 159 of 488 (33\%) patients endorsed ongoing cardiopulmonary symptoms including cough and dyspnea at 60 days [77•]. This study was limited by a large number of patients (greater than $50 \%$ ) being lost to follow-up.

While early studies estimated the prevalence of long COVID to be between 30 and $80 \%$, they were limited by a primary focus on hospitalized patients. Within a nonhospitalized cohort of 272 individuals across the USA, 35\% reported not being at baseline at 14-21 days after COVID-19 diagnosis [73]. New studies are using mobile technology to allow responders to directly monitor and report their symptoms for both acute and long-term tracking of symptoms [78, 79]. While older individuals with multiple comorbidities are at higher risk of long COVID, approximately $20 \%$ of young individuals, ages 18-34 and without comorbid conditions, also continued to report ongoing symptoms at 14-21 days [73].

With regards to specific cardiovascular symptoms, approximately $20 \%$ of individuals reported chest pain and $14 \%$ reported palpitations at 60 days $[76,80]$. Inflammation and increased metabolic and myocardial demand are thought to contribute to persistent cardiovascular symptoms as this has been seen in other severe coronavirus infections such as SARS [75, $81,82]$. A rising number of patients and case studies are also 
noting a relationship between COVID-19 and postural tachycardia syndrome (POTS) [83•]. POTS is characterized by change in heart rate with positional change, often accompanied by palpitations and decreased exercise tolerance [83•]. POTS has been previously linked to post-viral illness, but the exact mechanism is unknown $[84,85]$. One hypothesis connecting POTS with COVID-19 builds on its known interaction with the ACE2 protein expressed on neurons. Researchers hypothesize that this can disrupt the normal regulation of blood pressure mediated by ACE2, leading to hypotension and dysautonomia [74, 85]. Management of POTS and dysautonomia primarily centers on education, exercise, and salt and fluid repletion. Agents such as midodrine can improve vascular tone, while beta-blockers and ivabradine can help manage palpitations [86]. The prevalence, features, and management principles of long COVID are summarized in Fig. 3.

With $20-30 \%$ of outpatient individuals and up to $80 \%$ of hospitalized patients having persistent symptoms, the onus is now on providers and researchers to recognize and manage the persistent burden of COVID-19 infection. Many recover slowly on their own through anticipatory guidance and light exercise. However, the British Thoracic Society has established guidelines to follow up all patients regardless of severity at 12 weeks with a chest X-ray and clinical assessment to evaluate any need for further testing [87]. Those with severe COVID-19 are recommended to follow up earlier at 4 6 weeks to evaluate need for further testing as well as multidisciplinary rehabilitation [75]. Serial electrocardiograms and echocardiograms can be used to monitor those with persistent cardiac symptoms, although advanced imaging should be discussed on a case-by-case basis.

\section{Conclusion}

It has been some time since the global medical community has confronted a novel disease of pandemic proportions. Unraveling the mysteries of COVID-19 has been an exercise in diligent science and experimentation. The latest observational, pathologic, imaging, and clinical studies have clarified the short-term and long-term impacts of COVID-19 on the cardiovascular system and updated our understanding in a number of ways.
Fig. 3 Review of the prevalence of long COVID, definitions and symptomatic manifestations, and current principles of management for potential COVID/postural orthostatic tachycardia syndrome overlap
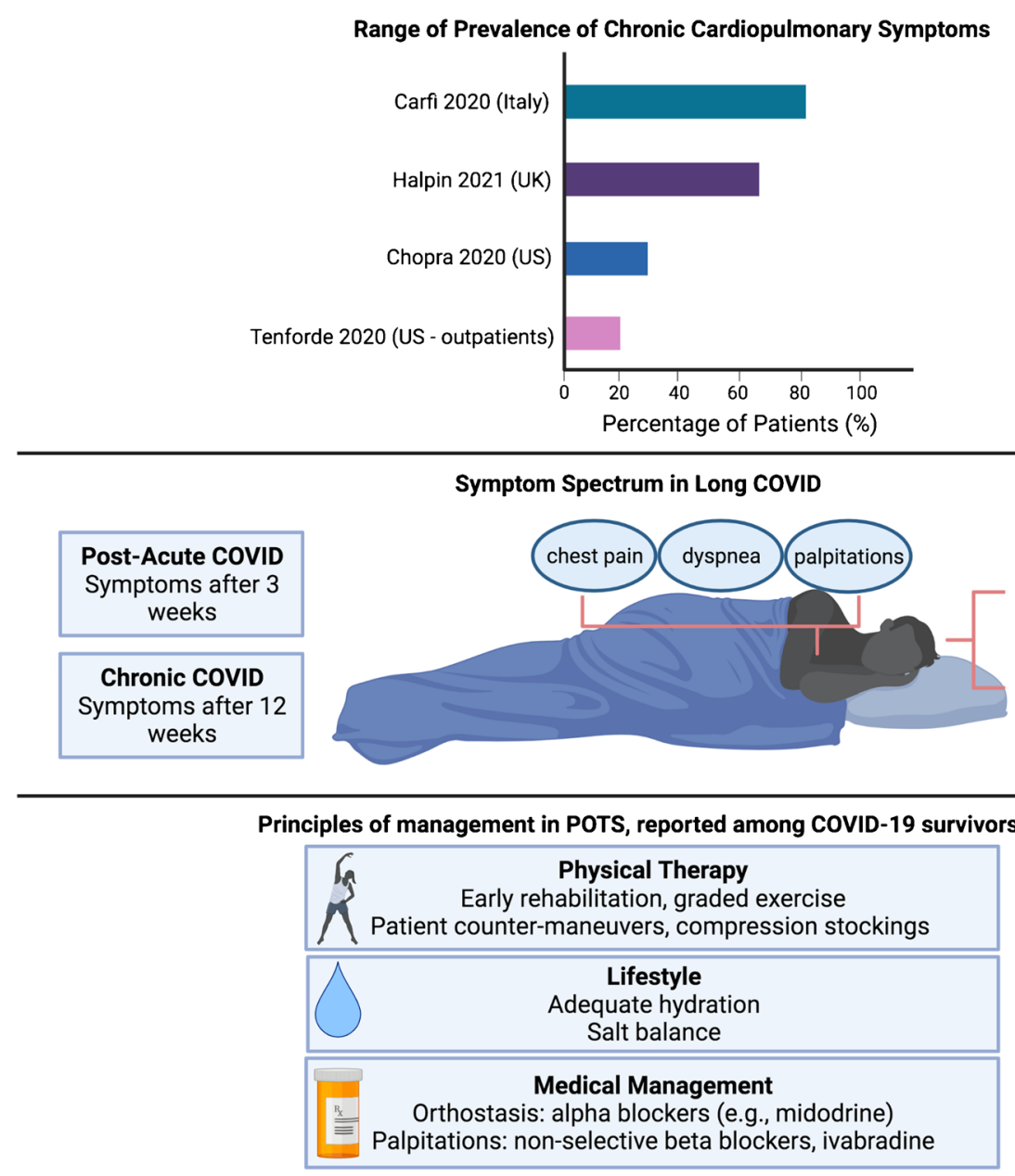


\section{Areas for Future Investigation: COVID-19 and Cardiovascular Disease}

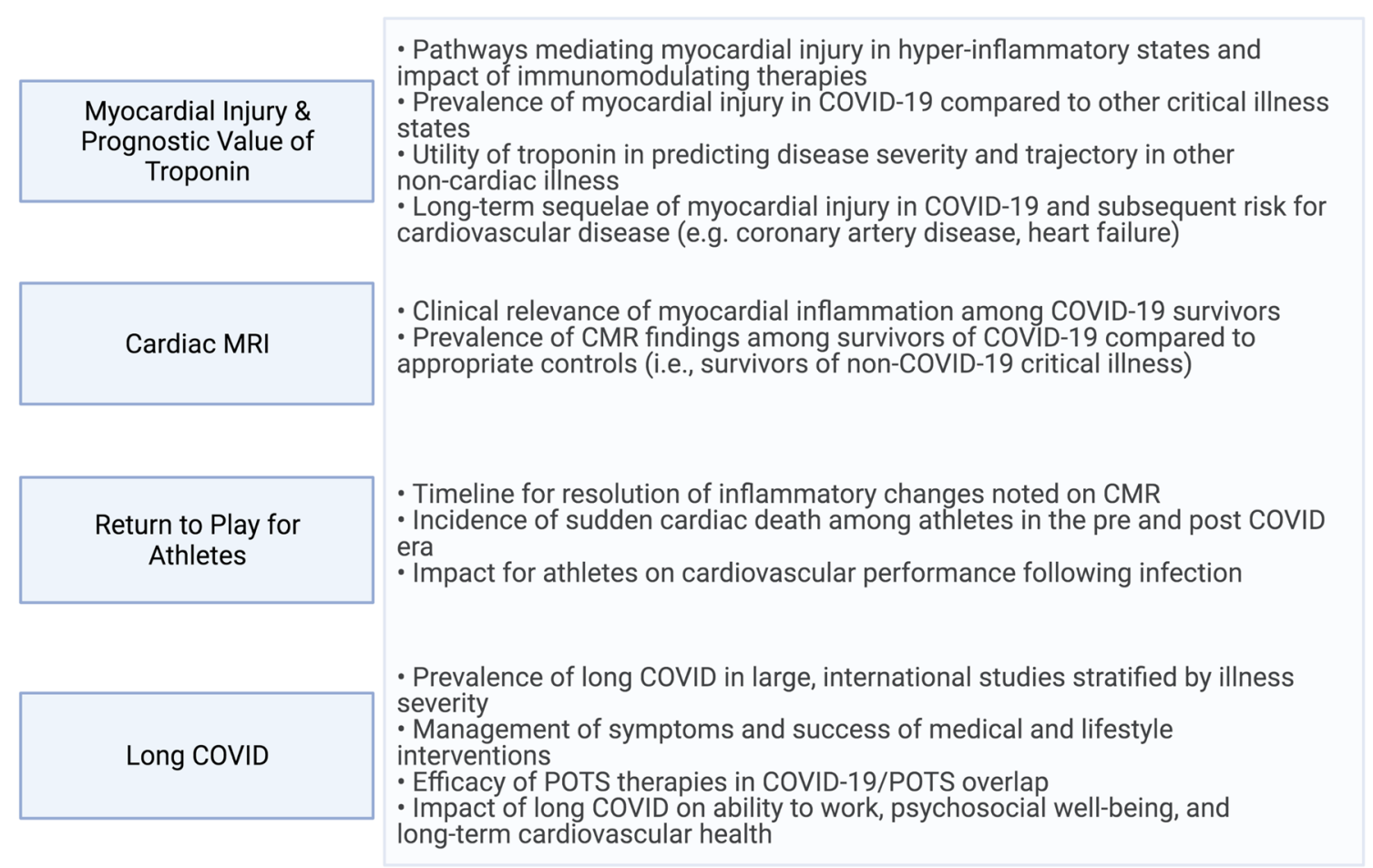

Fig. 4 Suggestions for future areas of investigation in the domains explored in this review. Abbreviations: POTS postural orthostatic tachycardia syndrome, CMR cardiac magnetic resonance

Myocardial injury in COVID-19 appears to be predominantly mediated by the severity of critical illness rather than direct injury to myocardium from viral particles. While myocardial injury is not unique to COVID-19 and is seen elsewhere in the critical care literature in sepsis and ARDS, the hyper-inflammatory response precipitated by COVID-19 is a unique hallmark and may mediate the more severe clinical courses seen as compared with other viruses. If anything, COVID-19 has reinforced the critical interaction between inflammation and CVD and should spur future work in this field. While myocardial injury in the form of troponin elevation is prevalent and prognostic in acute COVID-19 infection, recent studies suggest that troponin elevation is a marker of disease severity and the underlying substrate, rather than an independent mediator of outcomes.

While CMR remains a powerful tool for diagnosing acute myocarditis, it should be used judiciously in light of the low baseline prevalence established in studies to date, as well as risk of exposure to healthcare personnel. Studies are needed to understand the clinical relevance of persistent inflammatory signals seen in survivors and how this may compare or contrast with those recovering from other common viruses or critical illness. CMR may have a more focused role in providing recommendations for at-risk populations such as athletes; however, it should rarely be the first-line modality and imaging findings alone should not serve as the basis for diagnosing acute myocarditis.

Lastly, as we enter a new age of survivorship, additional research is needed to catalogue the burden of persistent cardiopulmonary symptoms which have significant implications for patient well-being and global economies regarding ability to return to work. Research is also needed to confirm whether existing therapies for dysautonomia including POTS are effective in the long COVID population, and how acute management may alter the likelihood and prevalence of this chronic syndrome. Future areas of investigation across the domains explored in this review are outlined in Fig. 4.

While questions remain and will continue to emerge regarding COVID-19 and CVD, the pandemic has proven that the scientific community is exceptionally committed and capable of providing these critical answers.

Acknowledgements The figures in this paper were created with BioRender.com.

Funding Dr Michos is supported by the Amato Fund for Women's Cardiovascular Health Research at Johns Hopkins University.

\section{Declarations}

Conflict of Interest The authors declare no competing interests.

Human and Animal Rights and Informed Consent This article does not contain any studies with human or animal subjects performed by any of the authors. 


\section{References}

Papers of particular interest, published recently, have been highlighted as:

- Of importance

•- Of major importance

1. Ahmad FB, Anderson RN. The leading causes of death in the US for 2020. JAMA. 2021. https://doi.org/10.1001/jama.2021.5469.

2•. Hendren NS, Drazner MH, Bozkurt B, Cooper LT Jr. Description and proposed management of the acute COVID-19 cardiovascular syndrome. Circulation. 2020;141(23):1903-14. https://doi.org/10. 1161/CIRCULATIONAHA.120.047349 This was one of the first papers to describe acute cardiovascular presentations of COVID-19 infection from epidemiology, pathogenesis, diagnosis, and treatment.

3. Clerkin KJ, Fried JA, Raikhelkar J, Sayer G, Griffin JM, Masoumi A, et al. COVID-19 and cardiovascular disease. Circulation. 2020;141(20):1648-55. https://doi.org/10.1161/ CIRCULATIONAHA.120.046941.

4. Khan MS, Shahid I, Anker SD, Solomon SD, Vardeny O, Michos ED, et al. Cardiovascular implications of COVID-19 versus influenza infection: a review. BMC Med. 2020;18(1):403. https://doi. org/10.1186/s12916-020-01816-2.

5. Duffy EY, Cainzos-Achirica M, Michos ED. Primary and secondary prevention of cardiovascular disease in the era of the coronavirus pandemic. Circulation. 2020;141(24):1943-5. https://doi.org/ 10.1161/CIRCULATIONAHA.120.047194.

6. Guo T, Fan Y, Chen M, Wu X, Zhang L, He T, et al. Cardiovascular implications of fatal outcomes of patients with coronavirus disease 2019 (COVID-19). JAMA Cardiol. 2020;5(7):811-8. https://doi. org/10.1001/jamacardio.2020.1017.

7. Atri D, Siddiqi HK, Lang JP, Nauffal V, Morrow DA, Bohula EA. COVID-19 for the cardiologist: basic virology, epidemiology, cardiac manifestations, and potential therapeutic strategies. JACC Basic Transl Sci. 2020;5(5):518-36. https://doi.org/10.1016/j. jacbts.2020.04.002.

8•. Usman MS, Siddiqi TJ, Khan MS, Ahmed A, Ali SS, Michos ED, et al. A Meta-analysis of the relationship between reninangiotensin-aldosterone system inhibitors and COVID-19. Am J Cardiol. 2020;130:159-61. https://doi.org/10.1016/j.amjcard. 2020.05.038 Addressing some hypothetical concerns raised early in the pandemic, this meta-analysis provided reassurance that there was no excess risk seen with the use of ACE inhibitors and angiotensin receptor blockers in the setting of COVID19 , and that patients prescribed these medications should continue to use them.

9. Minhas AS, Scheel P, Garibaldi B, Liu G, Horton M, Jennings M, et al. Takotsubo syndrome in the setting of COVID-19. JACC Case Rep. 2020;2(9):1321-5. https://doi.org/10.1016/j.jaccas.2020.04. 023.

10. Fried JA, Ramasubbu K, Bhatt R, Topkara VK, Clerkin KJ, Horn $\mathrm{E}$, et al. The variety of cardiovascular presentations of COVID-19. Circulation. 2020;141(23):1930-6. https://doi.org/10.1161/ CIRCULATIONAHA.120.047164.

11. Dherange P, Lang J, Qian P, Oberfeld B, Sauer WH, Koplan B, et al. Arrhythmias and COVID-19: a review. JACC Clin Electrophysiol. 2020;6(9):1193-204. https://doi.org/10.1016/j. jacep.2020.08.002

12. Castiello T, Georgiopoulos G, Finocchiaro G, Claudia M, Gianatti A, Delialis D, et al. COVID-19 and myocarditis: a systematic review and overview of current challenges. Heart Fail Rev. 2021. https://doi.org/10.1007/s10741-021-10087-9.
13. Puntmann VO, Carerj ML, Wieters I, Fahim M, Arendt C, Hoffmann J, et al. Outcomes of cardiovascular magnetic resonance imaging in patients recently recovered from coronavirus disease 2019 (COVID-19). JAMA Cardiol. 2020;5(11):1265-73. https:// doi.org/10.1001/jamacardio.2020.3557.

14. Goerlich E, Minhas AS, Mukherjee M, Sheikh FH, Gilotra NA, Sharma G, et al. Multimodality imaging for cardiac evaluation in patients with COVID-19. Curr Cardiol Rep. 2021;23(5):44. https:// doi.org/10.1007/s11886-021-01483-6.

15. Thygesen K, Alpert JS, Jaffe AS, Chaitman BR, Bax JJ, Morrow DA, et al. Fourth universal definition of myocardial infarction (2018). Circulation. 2018;138(20):e618-e51. https://doi.org/10. 1161/CIR.0000000000000617.

16. Kwong JC, Schwartz KL, Campitelli MA, Chung H, Crowcroft NS, Karnauchow T, et al. Acute myocardial infarction after laboratoryconfirmed influenza infection. N Engl J Med. 2018;378(4):345-53. https://doi.org/10.1056/NEJMoa1702090.

17. Chapman AR, Bularga A, Mills NL. High-sensitivity cardiac troponin can be an ally in the fight against COVID-19. Circulation. 2020;141(22):1733-5. https://doi.org/10.1161/ CIRCULATIONAHA.120.047008 This short article summarizes the various mechanisms of myocardial injury in COVID-19 that lead to elevation in cardiac troponin levels.

18. Jaffe AS, Cleland JGF, Katus HA. Myocardial injury in severe COVID-19 infection. Eur Heart J. 2020;41(22):2080-2. https:// doi.org/10.1093/eurheartj/ehaa447.

19. Shi S, Qin M, Shen B, Cai Y, Liu T, Yang F, et al. Association of cardiac injury with mortality in hospitalized patients with COVID19 in Wuhan, China. JAMA Cardiol. 2020;5(7):802-10. https://doi. org/10.1001/jamacardio.2020.0950.

20. Shi S, Qin M, Cai Y, Liu T, Shen B, Yang F, et al. Characteristics and clinical significance of myocardial injury in patients with severe coronavirus disease 2019. Eur Heart J. 2020;41(22):2070-9. https:// doi.org/10.1093/eurheartj/ehaa408.

21. Lippi G, Lavie CJ, Sanchis-Gomar F. Cardiac troponin I in patients with coronavirus disease 2019 (COVID-19): evidence from a metaanalysis. Prog Cardiovasc Dis. 2020;63(3):390-1. https://doi.org/ 10.1016/j.pcad.2020.03.001.

22. Bavishi C, Bonow RO, Trivedi V, Abbott JD, Messerli FH, Bhatt DL. Special article - Acute myocardial injury in patients hospitalized with COVID-19 infection: a review. Prog Cardiovasc Dis. 2020;63(5):682-9. https://doi.org/10.1016/j.pcad.2020.05.013.

23. Heffernan KS, Michos ED, Gump BB. Coronavirus disease 2019 (COVID-19) and cardiac injury. JAMA Cardiol. 2020;5:1198. https://doi.org/10.1001/jamacardio.2020.2450.

24•. Lala A, Johnson KW, Januzzi JL, Russak AJ, Paranjpe I, Richter F, et al. Prevalence and impact of myocardial injury in patients hospitalized with COVID-19 infection. J Am Coll Cardiol. 2020;76(5): 533-46. https://doi.org/10.1016/j.jacc.2020.06.007 This large study of over 2700 hospitalized patients with COVID highlighted the adverse prognosis associated with myocardial injury in the setting of COVID. The study showed that even after accounting for disease severity and clinical risk factors, even small elevations in cardiac troponin were associated with a $1.75 \times$ increased risk of death, and larger elevation of troponin associated with threefold risk of death.

25. Lombardi CM, Carubelli V, Iorio A, Inciardi RM, Bellasi A, Canale $\mathrm{C}$, et al. Association of troponin levels with mortality in Italian patients hospitalized with coronavirus disease 2019: Results of a Multicenter Study. JAMA Cardiol. 2020;5(11):1274-80. https:// doi.org/10.1001/jamacardio.2020.3538.

26. Oudit GY, Kassiri Z, Jiang C, Liu PP, Poutanen SM, Penninger JM, et al. SARS-coronavirus modulation of myocardial ACE2 expression and inflammation in patients with SARS. Eur J Clin Investig. 2009;39(7):618-25. https://doi.org/10.1111/j.1365-2362.2009. 02153.x. 
27. Xie J, Tong Z, Guan X, Du B, Qiu H. Clinical characteristics of patients who died of coronavirus disease 2019 in China. JAMA Netw Open. 2020;3(4):e205619. https://doi.org/10.1001/ jamanetworkopen.2020.5619.

28. Tomasoni D, Inciardi RM, Lombardi CM, Tedino C, Agostoni P, Ameri $\mathrm{P}$, et al. Impact of heart failure on the clinical course and outcomes of patients hospitalized for COVID-19. Results of the Cardio-COVID-Italy multicentre study. Eur J Heart Fail. 2020;22(12):2238-47. https://doi.org/10.1002/ejhf.2052.

29. Hosseinzadeh R, Goharrizi M, Bahardoust M, Alvanegh AG, Ataee MR, Bagheri M, et al. Should all patients with hypertension be worried about developing severe coronavirus disease 2019 (COVID-19)? Clin Hypertens. 2021;27(1):3. https://doi.org/10. 1186/s40885-021-00161-7.

30. Apicella M, Campopiano MC, Mantuano M, Mazoni L, Coppelli A, Del Prato S. COVID-19 in people with diabetes: understanding the reasons for worse outcomes. Lancet Diabetes Endocrinol. 2020;8(9):782-92. https://doi.org/10.1016/S2213-8587(20)302382.

31. Hendren NS, de Lemos JA, Ayers C, Das SR, Rao A, Carter S, et al. Association of body mass index and age with morbidity and mortality in patients hospitalized with COVID-19: results from the American Heart Association COVID-19 Cardiovascular Disease Registry. Circulation. 2021;143(2):135-44. https://doi.org/10. 1161/CIRCULATIONAHA.120.051936.

32•. Lindner D, Fitzek A, Brauninger H, Aleshcheva G, Edler C, Meissner K, et al. Association of cardiac infection with SARSCoV-2 in confirmed COVID-19 autopsy cases. JAMA Cardiol. 2020;5(11):1281-5. https://doi.org/10.1001/jamacardio.2020.3551 Contrary to prior speculations, this study showed that SARSCoV-2 is unlikely to be causing myocardial injury through direct myocardial invasion. The authors found that while viral RNA was isolated in cardiac tissue, in situ hybridization localized the site of infection not to cardiomyocytes, but rather to the interstitium and infiltrating macrophages. Additionally, there were zero confirmed cases of myocarditis by Dallas criteria.

33. Fox SE, Akmatbekov A, Harbert JL, Li G, Quincy Brown J, Vander Heide RS. Pulmonary and cardiac pathology in African American patients with COVID-19: an autopsy series from New Orleans. Lancet Respir Med. 2020;8(7):681-6. https://doi.org/10.1016/ S2213-2600(20)30243-5.

34. Bois MC, Boire NA, Layman AJ, Aubry MC, Alexander MP, Roden AC, et al. COVID-19-associated nonocclusive fibrin microthrombi in the heart. Circulation. 2021;143(3):230-43. https://doi.org/10.1161/CIRCULATIONAHA.120.050754.

35•. Metkus TS, Sokoll LJ, Barth AS, Czarny MJ, Hays AG, Lowenstein CJ, et al. Myocardial injury in severe COVID-19 compared with non-COVID-19 acute respiratory distress syndrome. Circulation. 2021;143(6):553-65. https://doi.org/10.1161/ CIRCULATIONAHA.120.050543 This study challenged prior notions that myocardial injury was more common in COVID19 than other critical illnesses. This study compared troponin elevation in COVID-19 ARDS vs non-COVID-19 ARDS among nearly 250 intubated patients across a large hospital system and demonstrated that myocardial injury was actually less common in COVID-19 than non-COVID-19 ARDS, after accounting for the degree of critical illness and organ dysfunction.

36. Sandoval Y, Januzzi JL Jr, Jaffe AS. Cardiac troponin for assessment of myocardial injury in COVID-19: JACC review topic of the week. J Am Coll Cardiol. 2020;76(10):1244-58. https://doi.org/10. 1016/j.jacc.2020.06.068.

37. Metkus TS, Guallar E, Sokoll L, Morrow D, Tomaselli G, Brower $\mathrm{R}$, et al. Prevalence and prognostic association of circulating troponin in the acute respiratory distress syndrome. Crit Care Med.
2017;45(10):1709-17. https://doi.org/10.1097/CCM. 0000000000002641 .

38. Metkus TS, Guallar E, Sokoll L, Morrow DA, Tomaselli G, Brower $\mathrm{R}$, et al. Progressive myocardial injury is associated with mortality in the acute respiratory distress syndrome. J Crit Care. 2018;48:2631. https://doi.org/10.1016/j.jcrc.2018.08.009.

39. Masson S, Caironi P, Fanizza C, Carrer S, Caricato A, Fassini P, et al. Sequential N-terminal pro-B-type natriuretic peptide and highsensitivity cardiac troponin measurements during albumin replacement in patients with severe sepsis or septic shock. Crit Care Med. 2016;44(4):707-16. https://doi.org/10.1097/CCM. 0000000000001473.

40. Li D, Chen Y, Jia Y, Tong L, Tong J, Wang W, et al. SARS-CoV-2induced immune dysregulation and myocardial injury risk in China: insights from the ERS-COVID-19 study. Circ Res. 2020;127(3): 397-9. https://doi.org/10.1161/CIRCRESAHA.120.317070.

41. Rosado FG, Kim AS. Hemophagocytic lymphohistiocytosis: an update on diagnosis and pathogenesis. Am J Clin Pathol. 2013;139(6):713-27. https://doi.org/10.1309/ AJCP4ZDKJ4ICOUAT.

42. Perez AL, Grodin JL, Chaikijurajai T, Wu Y, Hernandez AF, Butler $\mathrm{J}$, et al. Interleukin- 6 and outcomes in acute heart failure: an ASCEND-HF substudy. J Card Fail. 2021. https://doi.org/10. 1016/j.cardfail.2021.01.006.

43. Szekely Y, Lichter Y, Taieb P, Banai A, Hochstadt A, Merdler I, et al. Spectrum of cardiac manifestations in COVID-19: a systematic echocardiographic study. Circulation. 2020;142(4):342-53. https://doi.org/10.1161/CIRCULATIONAHA.120.047971.

44. Giustino G, Croft LB, Stefanini GG, Bragato R, Silbiger JJ, Vicenzi $\mathrm{M}$, et al. Characterization of myocardial injury in patients with COVID-19. J Am Coll Cardiol. 2020;76(18):2043-55. https://doi. org/10.1016/j.jacc.2020.08.069.

45. Goerlich E, Gilotra NA, Minhas AS, Bavaro N, Hays AG, Cingolani OH. Prominent longitudinal strain reduction of basal left ventricular segments in patients with coronavirus disease-19. J Card Fail. 2021;27(1):100-4. https://doi.org/10.1016/j.cardfail. 2020.09.469.

46. Smilowitz NR, Jethani N, Chen J, Aphinyanaphongs Y, Zhang R, Dogra S, et al. Myocardial injury in adults hospitalized with COVID-19. Circulation. 2020;142(24):2393-5. https://doi.org/10. 1161/CIRCULATIONAHA.120.050434.

47. Qin JJ, Cheng X, Zhou F, Lei F, Akolkar G, Cai J, et al. Redefining cardiac biomarkers in predicting mortality of inpatients with COVID-19. Hypertension. 2020;76(4):1104-12. https://doi.org/ 10.1161/HYPERTENSIONAHA.120.15528.

48. Stefanini GG, Chiarito M, Ferrante G, Cannata F, Azzolini E, Viggiani G, et al. Early detection of elevated cardiac biomarkers to optimise risk stratification in patients with COVID-19. Heart. 2020;106(19):1512-8. https://doi.org/10.1136/heartjnl-2020317322.

49. Sanghvi SK, Schwarzman LS, Nazir NT. Cardiac MRI and myocardial injury in COVID-19: diagnosis, risk stratification and prognosis. Diagnostics. 2021;11(1). https://doi.org/10.3390/ diagnostics11010130.

50. Ruan Q, Yang K, Wang W, Jiang L, Song J. Clinical predictors of mortality due to COVID-19 based on an analysis of data of 150 patients from Wuhan, China. Intensive Care Med. 2020;46(5):8468. https://doi.org/10.1007/s00134-020-05991-x.

51. Driggin E, Madhavan MV, Bikdeli B, Chuich T, Laracy J, BiondiZoccai G, et al. Cardiovascular considerations for patients, health care workers, and health systems during the COVID-19 pandemic. J Am Coll Cardiol. 2020;75(18):2352-71. https://doi.org/10.1016/ j.jacc.2020.03.031.

52. Lagana N, Cei M, Evangelista I, Cerutti S, Colombo A, Conte L, et al. Suspected myocarditis in patients with COVID-19: a 
multicenter case series. Medicine. 2021;100(8):e24552. https://doi. org/10.1097/MD.0000000000024552.

53. Skulstad H, Cosyns B, Popescu BA, Galderisi M, Salvo GD, Donal E, et al. COVID-19 pandemic and cardiac imaging: EACVI recommendations on precautions, indications, prioritization, and protection for patients and healthcare personnel. Eur Heart J Cardiovasc Imaging. 2020;21(6):592-8. https://doi.org/10.1093/ehjci/jeaa072.

54. Han Y, Chen T, Bryant J, Bucciarelli-Ducci C, Dyke C, Elliott MD, et al. Society for Cardiovascular Magnetic Resonance (SCMR) guidance for the practice of cardiovascular magnetic resonance during the COVID-19 pandemic. J Cardiovasc Magn Reson. 2020;22(1):26. https://doi.org/10.1186/s12968-020-00628-w.

55•. Rudski L, Januzzi JL, Rigolin VH, Bohula EA, Blankstein R, Patel $\mathrm{AR}$, et al. Multimodality imaging in evaluation of cardiovascular complications in patients with COVID-19: JACC Scientific Expert Panel. J Am Coll Cardiol. 2020;76(11):1345-57. https://doi.org/10. 1016/j.jacc.2020.06.080 This expert panel from the ACC recommends CMR only after CAD has been ruled out by angiography or less invasive modalities, such as CCTA, because the pre-test probability of ischemia is much more likely than acute myocarditis.

56. Huang L, Zhao P, Tang D, Zhu T, Han R, Zhan C, et al. Cardiac involvement in patients recovered from COVID-2019 identified using magnetic resonance imaging. JACC Cardiovasc Imaging. 2020;13(11):2330-9. https://doi.org/10.1016/j.jcmg.2020.05.004.

57. Siddiqui Y, Crouser ED, Raman SV. Nonischemic myocardial changes detected by cardiac magnetic resonance in critical care patients with sepsis. Am J Respir Crit Care Med. 2013;188(8): 1037-9. https://doi.org/10.1164/rccm.201304-0744LE.

58. Maron BJ, Doerer JJ, Haas TS, Tierney DM, Mueller FO. Sudden deaths in young competitive athletes: analysis of 1866 deaths in the United States, 1980-2006. Circulation. 2009;119(8):1085-92. https://doi.org/10.1161/CIRCULATIONAHA.108.804617.

59. La Gerche A, Taylor AJ, Prior DL. Athlete's heart: the potential for multimodality imaging to address the critical remaining questions. JACC Cardiovasc Imaging. 2009;2(3):350-63. https://doi.org/10. 1016/j.jcmg.2008.12.011.

60. Shave R, Baggish A, George K, Wood M, Scharhag J, Whyte G, et al. Exercise-induced cardiac troponin elevation: evidence, mechanisms, and implications. J Am Coll Cardiol. 2010;56(3):169-76. https://doi.org/10.1016/j.jacc.2010.03.037.

61. Phelan D, Kim JH, Chung EH. A game plan for the resumption of sport and exercise after coronavirus disease 2019 (COVID-19) infection. JAMA Cardiol. 2020;5:1085-6. https://doi.org/10.1001/ jamacardio.2020.2136.

62. Maron BJ, Udelson JE, Bonow RO, Nishimura RA, Ackerman MJ, Estes NA 3rd, et al. Eligibility and disqualification recommendations for competitive athletes with cardiovascular abnormalities: task force 3: hypertrophic cardiomyopathy, arrhythmogenic right ventricular cardiomyopathy and other cardiomyopathies, and myocarditis: a scientific statement from the American Heart Association and American College of Cardiology. Circulation. 2015;132(22): e273-80. https://doi.org/10.1161/CIR.0000000000000239.

63. Kim JH, Levine BD, Phelan D, Emery MS, Martinez MW, Chung $\mathrm{EH}$, et al. Coronavirus disease 2019 and the athletic heart: emerging perspectives on pathology, risks, and return to play. JAMA Cardiol. 2021;6(2):219-27. https://doi.org/10.1001/jamacardio.2020.5890.

64. Phelan D, Kim JH, Elliott MD, Wasfy MM, Cremer P, Johri AM, et al. Screening of potential cardiac involvement in competitive athletes recovering from COVID-19: An Expert Consensus Statement. JACC Cardiovasc Imaging. 2020;13(12):2635-52. https://doi.org/10.1016/j.jcmg.2020.10.005.

65. Rajpal S, Tong MS, Borchers J, Zareba KM, Obarski TP, Simonetti $\mathrm{OP}$, et al. Cardiovascular magnetic resonance findings in competitive athletes recovering from COVID-19 infection. JAMA Cardiol. 2021;6(1):116-8. https://doi.org/10.1001/jamacardio.2020.4916.
66. Brito D, Meester S, Yanamala N, Patel HB, Balcik BJ, CasaclangVerzosa G, et al. High prevalence of pericardial involvement in college student athletes recovering from COVID-19. JACC Cardiovasc Imaging. 2021;14(3):541-55. https://doi.org/10.1016/ j.jcmg.2020.10.023

67••. Martinez MW, Tucker AM, Bloom OJ, Green G, DiFiori JP, Solomon G, et al. Prevalence of inflammatory heart disease among professional athletes with prior COVID-19 infection who received systematic return-to-play cardiac screening. JAMA Cardiol. 2021. https://doi.org/10.1001/jamacardio.2021.0565 This reassuring registry data showed that the national return to play for athletes has been a safe endeavor. This study of $\mathbf{7 8 9}$ professional athletes that underwent a RTP cardiac testing protocol after COVID-19 infection found imaging evidence of inflammatory heart disease in only $0.6 \%$.

68. Couzin-Frankel J. The long haul. Science. 2020;369(6504):614-7. https://doi.org/10.1126/science.369.6504.614.

69. Greenhalgh T, Knight M, A'Court C, Buxton M, Husain L. Management of post-acute covid-19 in primary care. BMJ. 2020;370:m3026. https://doi.org/10.1136/bmj.m3026.

70. Dani M, Dirksen A, Taraborrelli P, Torocastro M, Panagopoulos D, Sutton R, et al. Autonomic dysfunction in 'long COVID': rationale, physiology and management strategies. Clin Med. 2021;21(1):e63e7. https://doi.org/10.7861/clinmed.2020-0896.

71. National Institute of Health. https://www.nih.gov/about-nih/whowe-are/nih-director/statements/nih-launches-new-initiative-studylong-covid. Accessed April 5, 2020.

72. Halpin SJ, McIvor C, Whyatt G, Adams A, Harvey O, McLean L, et al. Postdischarge symptoms and rehabilitation needs in survivors of COVID-19 infection: a cross-sectional evaluation. J Med Virol. 2021;93(2):1013-22. https://doi.org/10.1002/jmv.26368.

73. Tenforde MW, Kim SS, Lindsell CJ, Billig Rose E, Shapiro NI, Files DC, et al. Symptom duration and risk factors for delayed return to usual health among outpatients with COVID-19 in a multistate health care systems network - United States, MarchJune 2020. MMWR Morb Mortal Wkly Rep. 2020;69(30):993-8. https://doi.org/10.15585/mmwr.mm6930e1.

74. Lo YL. COVID-19, fatigue, and dysautonomia. J Med Virol. 2021;93(3):1213. https://doi.org/10.1002/jmv.26552.

75. Nalbandian A, Sehgal K, Gupta A, Madhavan MV, McGroder C, Stevens JS, et al. Post-acute COVID-19 syndrome. Nat Med. 2021;27:601-15. https://doi.org/10.1038/s41591-021-01283-z.

76. Carfi A, Bernabei R, Landi F. Gemelli Against COVID-19 PostAcute Care Study Group. Persistent symptoms in patients after acute COVID-19. JAMA. 2020;324(6):603-5. https://doi.org/10. 1001/jama.2020.12603.

77. Chopra V, Flanders SA, O’Malley M, Malani AN, Prescott HC. Sixty-day outcomes among patients hospitalized with COVID-19. Ann Intern Med. 2020. https://doi.org/10.7326/M20-5661 This study evaluating patients 60 days after COVID-19 hospitalization identified that a significant proportion of patients still had residual symptoms, as well as mental and financial stressors. This study highlights that for many patients, it is not over after their discharge home.

78. Drew DA, Nguyen LH, Steves CJ, Menni C, Freydin M, Varsavsky $\mathrm{T}$, et al. Rapid implementation of mobile technology for real-time epidemiology of COVID-19. Science. 2020;368(6497):1362-7. https://doi.org/10.1126/science.abc0473.

79. Sudre CH, Murray B, Varsavsky T, Graham MS, Penfold RS, Bowyer RC et al. Attributes and predictors of long-COVID: analysis of COVID cases and their symptoms collected by the Covid Symptoms Study App. medRxiv. 2020:2020.10.19.20214494. https://doi.org/10.1101/2020.10.19.20214494.

80. Carvalho-Schneider C, Laurent E, Lemaignen A, Beaufils E, Bourbao-Tournois C, Laribi S, et al. Follow-up of adults with noncritical COVID-19 two months after symptom onset. Clin 
Microbiol Infect. 2021;27(2):258-63. https://doi.org/10.1016/j. cmi.2020.09.052.

81. Wu Q, Zhou L, Sun X, Yan Z, Hu C, Wu J, et al. Altered lipid metabolism in recovered SARS patients twelve years after infection. Sci Rep. 2017;7(1):9110. https://doi.org/10.1038/s41598-01709536-z.

82. Madjid M, Safavi-Naeini P, Solomon SD, Vardeny O. Potential effects of coronaviruses on the cardiovascular system: a review. JAMA Cardiol. 2020;5(7):831-40. https://doi.org/10.1001/ jamacardio.2020.1286.

83 • Johansson M, Stahlberg M, Runold M, Nygren-Bonnier M, Nilsson J, Olshansky B, et al. Long-haul post-COVID-19 symptoms presenting as a variant of postural orthostatic Tachycardia syndrome: the Swedish experience. JACC Case Rep. 2021. https://doi.org/10.1016/j.jaccas.2021.01.009 This case series called attention to a rising number of patients and case studies with postural tachycardia syndrome (POTS) following COVID-19.
84. Fedorowski A. Postural orthostatic tachycardia syndrome: clinical presentation, aetiology and management. J Intern Med. 2019;285(4):352-66. https://doi.org/10.1111/joim.12852.

85. Goldstein DS. The possible association between COVID-19 and postural tachycardia syndrome. Heart Rhythm. 2021;18(4):508-9. https://doi.org/10.1016/j.hrthm.2020.12.007.

86. Bryarly M, Phillips LT, Fu Q, Vernino S, Levine BD. Postural orthostatic tachycardia syndrome: JACC focus seminar. J Am Coll Cardiol. 2019;73(10):1207-28. https://doi.org/10.1016/j.jacc. 2018.11.059.

87. George PM, Barratt SL, Condliffe R, Desai SR, Devaraj A, Forrest I, et al. Respiratory follow-up of patients with COVID-19 pneumonia. Thorax. 2020;75(11):1009-16. https://doi.org/10.1136/ thoraxjnl-2020-215314.

Publisher's Note Springer Nature remains neutral with regard to jurisdictional claims in published maps and institutional affiliations. 